\title{
AS CONTRIBUIÇÕES DO PROGRAMA RESIDÊNCIA PEDAGÓGICA PARA FORMAÇÃO DOCENTE
}

The contributions of the pedagogical residence program for teaching training

Las contribuciones del programa de residencia pedagógica para la formación docente

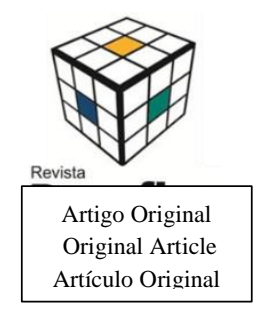

\section{Nilciane Pinto Ribeiro de Sousa ${ }^{1}$, Leonardo Cipriano Nogueira ${ }^{2}$, Gecilane Ferreira ${ }^{3}$, Rodney Haulien Oliveira Viana ${ }^{4}$.}

${ }^{1}$ Mestranda em Ensino de Ciências e Matemática, Universidade Federal do Tocantins, Araguaína-TO, Brasil. ${ }^{2}$ Mestrando em Ensino de Ciências e Matemática, Universidade Federal do Tocantins, Araguaína-TO, Brasil. ${ }^{3}$ Doutor em Educação em Ciências e Matemática, Professor do Programa de Pós-Graduação em Ensino de Ciências e Matemática, Universidade Federal do Tocantins, Araguaína-TO, Brasil.

${ }^{4}$ Doutor em Botânica, Professor do Programa de Pós-Graduação em Ensino de Ciências e Matemática, Universidade Federal do Tocantins, Araguaína-TO, Brasil.

\section{Artigo recebido em 03/04/2020 aprovado em 09/04/2020 publicado em 17/04/2020.}

\section{INTRODUÇÃO}

O processo de formação de professores é uma atividade bastante complexa tendo em vista que a mobilização de indivíduos em busca de construção de conhecimento não é uma tarefa fácil.

Durante a formação, o docente passa pelo processo de construção de identidade. É um desenvolvimento da sua personalidade, essa construção atravessa toda a vida profissional desde a fase de escolha e decisão pela docência, a constituição formal, os espaços institucionais nos quais sua atuação se desenrola (BESUTTI; REDANTE; FÁVERO, 2017).

Para Pimenta (1996) a identidade profissional de um docente é construída pela significação dada pelo professor a sua profissão, enquanto autor e ator, conferindo à atividade docente no seu cotidiano a partir de seus valores, de seu modo de situar-se no mundo, de sua história de vida, de suas representações, de seus saberes, de suas angústias e de seus anseios.

Milaré e Filho (2010) aponta que existem dificuldades na formação inicial dos professores, pois apresenta deficiências tanto na formação específica quanto na pedagógica. Uma formação adequada possibilita ao professor atuar com segurança, incluindo elementos que contextualizem os conteúdos que desenvolve em sua prática.

A criação de projetos e programas que fomentem uma formação docente de qualidade vem ganhando força, com isso os programas institucionais estão crescendo e se estabelecendo nesse cenário como o Programa Residência Pedagógica (PRP), que em maior escala visa atender essas necessidades tornado as atividades que antes eram realizadas pelos estágios supervisionados com menos intensidade, agora de forma mais dinâmicas e mais evidente na formação inicial de professores.

Programas como o Residência Pedagógica, assume papeis essenciais e necessários na formação de um professor. Dando a ele suporte, compreensão, verificação da realidade, experiência, noção, troca de saberes, apropriação do exercício de prática, dentre muitos outros fatores benéficos que podem com certeza serem adquiridos.

Dessa forma, compreendendo a formação inicial como uma das principais fases na formação de um profissional da educação e, sendo o Programa Residência Pedagógica um importante aliado para a melhoria da formação docente, este trabalho visa 
promover discussões acerca das contribuições proporcionadas pelo PRP para a formação docente.

\section{METODOLOGIAS E MATERIAIS}

Trata-se de uma pesquisa de cunho qualitativo realizada através de pressupostos metodológicos da análise documental, onde foram analisados os relatórios dos residentes da etapa três do PRP núcleo de Biologia de uma escola campo de Araguaína Tocantins.

Para análise dos documentos foram analisados somente aspectos que salientavam as contribuições do programa relacionados as experiências concedidas pelo mesmo, para isso foi atribuído um código para cada relatório (Quadro- 1) com objetivo de apoiar as análises e resguardar a identidade dos colaboradores e autores dos relatórios.

\begin{tabular}{|c|c|c|}
\hline Iricial do aut or & Etapa & Código atr ibuído \\
\hline AN & 3 & AN3 \\
\hline AND & 3 & AND3 \\
\hline JA & 3 & JA3 \\
\hline ROM & 3 & RO3 \\
\hline ROS & 3 & ROS3 \\
\hline VA & 3 & VA3 \\
\hline
\end{tabular}

Quadro -1. Quadro com as iniciais dos autores do relatório, etapa que foi desenvolvido no PRP e a sigla atribuída.

\section{RESULTADOS E DISCUSSÃO}

A proposta de um programa de formação de professores denominada Residência Pedagógica, nos possibilita uma perspectiva crítico-reflexiva em direção à profissionalização do ofício de ensinar. É sem dúvida um grande desafio. De modo geral, os docentes responsáveis pela formação inicial de professores vêm utilizando, junto aos residentes (licenciando em biologia), estratégias que procuram favorecer um processo reflexivo sobre suas práticas nos estágios supervisionados.

São característicos dessas estratégias, os cadernos de campo, as reuniões e discussões com os residentes e entre os professores preceptores com coordenador do núcleo, a elaboração de microaulas e de relatórios com a finalidade de analisar as atividades didáticas desenvolvidas, as observações e análises de aulas dos professores preceptores, produção científica e participação de debates e seminários em outras atividades de cunho acadêmico de iniciação docente.

$$
\text { A Residência Pedagógica tem como }
$$
premissas básicas o entendimento de que a formação de professores nos cursos de licenciatura deve assegurar aos seus egressos, habilidades e competências que lhes permitam realizar um ensino de qualidade nas escolas de educação básica. Com isso, o PRP vem aproximar o acadêmico ao ambiente escolar, trazendo-os ao cotidiano da vida docente.

Os residentes se mostraram bastante motivados com o programa e com as propostas desenvolvidas em conjunto como os projetos e as ações do programa na escola e na Universidade. Segundo relato do residente

VA3: "O programa pôde contemplar a criação de um espaço de formação diferenciado, que criou oportunidades para a troca de experiências entre os profissionais, aprimorando a formação docente por meio da necessária articulação entre o que eu aprendi na universidade e o que experienciei na prática da residência, para que assim, pudesse desenvolver a capacidade de relacionar teoria e prática docente em novas metodologias de ensino $e$ aprendizagem”.

Nesse trecho percebemos que a dinamicidade oferecida pelas atividades do PRP concede experiências com vários profissionais no âmbito escolar, onde o residente encontra-se inserido, trazendo reflexões das práticas docentes da academia com prática cotidiana. Nóvoa (2009) reintegra que "a formação de um professor encerra uma complexidade que só se obtém a partir da integração numa cultura profissional".

JA3: "Com o programa, pude aprimorar meus saberes, como agir diante de alguns problemas e dificuldades que forem surgindo, tentar buscar meios de proporcionar aos educandos aulas mais lúdicas e dinâmicas, mesmo que não tenha materiais ou recursos disponíveis porque sabemos das realidades das 
nossas escolas públicas. Todas as orientações realizadas durante o período de regência foram de grande importância e contribuiu muito para meu desenvolvimento e conclusão do Programa".

O relato demonstra que a residente vivenciou situações que contribuíram no que diz respeito a compreender que os desafios são formas de aprendizado, que nos possibilita utilizar da criatividade para solucionar problemas. Brito (2016) descreve que "Para quem lida com a formação de professores, esse Programa, juntamente com os Estágios Supervisionados e com outros que atuam na relação com a realidade da Educação Básica, permite inserir os licenciandos no "olho do furacão" - único lugar possível se se quer formar um professor".

AN3: "Além do aprendizado durante o período de regência, esse também teve dificuldades, como por exemplo, conseguir controlar uma turma cheia após o recreio.",

AN3: "O programa Residência Pedagógica foi uma experiência válida e que com certeza mudou minha visão do que é ser professor na prática, e só confirmando que não é uma profissão fácil, mas que tem muitos encantos".

Esses relatos evidenciam a riqueza das experiências vivenciadas e assim como a realidade do "chão da sala de aula" propiciando os residentes perceberem as contribuições a cerca desses momentos, e reintegra que é uma tarefa desafiadora possibilitando tomada de decisão no que concerne a identidade profissional docente.

ROS3: "A Residência Pedagógica, contribuiu em diversos fatores para a formação dos residentes. Com relação a formação profissional ela proporcionou melhor desenvolvimento na elaboração de atividades em sala de aula, assim como também melhorou a desenvoltura na forma de atuar como futuro docente."

Nesse momento identificamos um importante retorno da prática em relação à didática na formação oferecida pelos programas de iniciação à docência, construindo conhecimento e dando segurança ao futuro docente em relação a sua prática pedagógica.

\section{CONCLUSÃO}

Desta forma foi identificado que o PRP promove aprendizado no que tange as contribuições proporcionadas pelas experiências práticas. As dificuldades encontradas no caminho tornaram-se aprendizado, agregando aos envolvidos nesse processo de construção de conhecimentos em relação à docência e inovação educacional. O programa propicia um aprendizado valioso e uma reflexão sobre a importância entre o vínculo da academia com as escolas, proporcionando grande contribuição na formação inicial e continuada dos participantes.

\section{AGRADECIMENTO}

A Universidade Federal do Tocantins e ao Programa Residência Pedagógica - CAPES, Aos gestores da escola campo e em especial ao Núcleo de Biologia de Araguaína, ao Preceptor da escola campo analisada, Professor Orientador, e os Residentes envolvidos no PRP.

Todos os autores declararam não haver qualquer potencial conflito de interesses referente a este artigo. 


\section{REFERÊNCIAS}

BESUTTI, J.; REDANTE, R.C.; FÁVERO, A.A.

Formação e construção da identidade docente a partir da narrativa de histórias de vida. Educação Por Escrito. Porto Alegre, v. 8, n. 2, p. 260-277, jul./dez. 2017.

BRITO, L. D. Contribuições de um programa de iniciação à docência à formação de futuros professores de Ciências. Revista Iberoamericana de Educación, [s.1.], v. 72, n. 2, p.103-120, 15 nov. 2016.

NÓVOA, António. Para uma formação de professores construída dentro da profissão. Revista de Educación, [s.1.], v. 350, n. 350, p.203-2018, fev. 2009.

MILARÉ, T.; ALVES FILHO, J.P.de. Ciências no nono ano do Ensino Fundamental: da disciplinaridade à alfabetização científica e tecnológica. Rev. Ensaio. v.12, n.2, p. 101-120, 2010.

PIMENTA, S.G. Formação de Professores - Saberes da Docência e Identidade do Professor.

Rev.Fac.Educ. São Paulo, v.22, n2 p.72-89, jul./dez.1996. 